\title{
Senior population employment as a factor of rural areas sustainable development
}

\author{
Olga Rubaeva $^{1}$, Natalia Pakhomova ${ }^{1}$, and Tatyana Nikitina ${ }^{1, *}$ \\ ${ }^{1}$ South Ural State Agrarian University, 75, Lenin Prospect St., 454080, Chelyabinsk, Russia \\ ${ }^{2}$ Chelyabinsk State University, 129, Kashirin Br. St. 454001, Chelyabinsk, Russia
}

\begin{abstract}
The study aims to develop an informative model for the preparation of employment for seniors in rural areas. Aging of the rural population puts additional demographic pressure on the economy and is a factor in the sustainable development of rural areas, which play a significant role in ensuring food self-sufficiency in the region. The study was conducted in rural areas of the Chelyabinsk region. There was an analytical study of the demographic structure of villagers. There was studied employment and age structure of villagers. With the help of the economic-mathematical method there were calculated the employment rates of elderly people in rural areas, there were assessed the possibilities of involving older people to work in the real economy. The study includes three hypotheses explaining the relationship of the qualitative characteristics of employment of the seniors, the elderly and their reflection in the strategic development programs of rural areas, providing training for seniors. During the study and research it was found that all the hypotheses were confirmed. Thus, the informative model of employment provision of seniors in rural areas is practical importance and can be recommended for implementation in other rural areas.
\end{abstract}

\section{Introduction}

One of the factors of sustainable development of rural areas is the aging of the rural population, which exerts an additional demographic burden on the economy of these territories.

Currently in Russia the demographic load on the economy is increasing due to the aging population. Therefore the problem of developing an informative model for the research of the preparation of employment for seniors in rural areas is viewed as an objective necessity. Decision of the designated problem often boils down to a change in the retirement age and a quantitative increase in the participation of older people in the real sector of the economy. Labor for many seniors is not only an additional income, but also an improvement in the quality of their life. The characteristic of quality employment of older people, which would reflect the need for growth in productive labor in the real economy and decent wages, is not fully taken into account.

\footnotetext{
*Corresponding author: tnikitina24@mail.ru
} 
The established practice, the lack of mechanisms and methods for using the labor potential of seniors displaces them to low-quality jobs. This generally discredits the elderly population. It is necessary to change this situation, and for this purpose it is necessary to conduct scientific research on the formation and development of employment mechanisms for the elderly.

Therefore, there is the urgency of conducting this study, which will allow in practice to adapt the information model of the study on the preparation of employment for the elderly in rural areas, to develop mechanisms and methods for the formation of employment for the elderly in the real sector of the economy.

\section{Materials and methods}

The theoretical and methodological basis of the study is the scientific works of domestic and foreign scientists related to the study of demographic factors of sustainable socioeconomic development of rural areas.

The information base of the study was made up of official data from the Federal State Statistics Service and its territorial divisions.

In this study the monographic method, the economic-mathematical and the informationlogical modeling method were used.

Many domestic scientists are involved in employment issues. In particular, V. N. Bobkov, V. G. Kvachev, N. V. Loktyukhina, M. Ricceri investigated the problem of unstable employment in the regions of the Russian Federation [1]. From their point of view, precarious employment is "a multilevel phenomenon of the socio-economic instability positions of employees" and can be defined "both in terms of the quality and nature of the employment contract and working conditions, and in terms of the living standards of households of unstable workers, their subjective self-perception and behavioral patterns in the labor market and in other areas of life" [2].

Issues of socio-economic development of territorial systems are reflected in many works of domestic researchers [3].

Socio-economic potential and its reserve is available in most regions of the Russian Federation [4].

When developing and implementing an effective socio-economic policy in the country, the patterns of territorial distribution of the population and the motivating factors of population mobility should be taken into account $[5 ; 6]$. These research results can be applied both at the regional level and at the municipal level [7].

In a comprehensive assessment of the socio-economic development of regions, the main goal is to develop the possibility of solving strategic development objectives based on spatial, geographical, natural, socio-institutional and other features [8].

Much research has also been devoted to questions of the correlation between socio-demographic and economic processes. In particular, O. A. Kozlova, R. V. Nifantova, M. N. Makarova proposed a methodology for assessing the economic damage from mortality of the population. The proposed methodological instrumentation allows to estimate the economic losses of society from the mortality of the working-age population employed in the economy [9].

Many scientists also concern the problem of human resource shortages in a developing regional economy [10]. For the rational using of labor resources the special software was developed, which makes it possible to make a realistic prediction of compliance with the level of labor migration, population reproduction and the pace of economic development based on statistics [11].

In the process of analyzing socio-economic indicators, such as the retirement age, the size and structure of pension payments, the procedure for transferring pension contributions 
and other indicators, there were identified the main priorities for cooperation between the EEU countries, especially: "Development of general principles of social guarantees for persons of retirement age, practical measures for the implementation of a guaranteed income program for persons of retirement age, development of common approaches to the regulation of investment activities of pension funds, formation of a unified information base for pension benefits" [12].

Some scientists' researches are devoted to problems in the field of human capital territorial systems. V. A. Iontsev and A. G. Magomedova analyzed the current demographic situation of the Russian Federation, which scientists have identified as the "demographic crisis" [13].

Researchers give priority to the demographic factor in the formation and development of human capital, moreover, they note the important position of population migration [14]. In one of the works, the authors propose a calculation of the human potential index, which can be determined both at the regional level and at the state level as a whole [15].

Many scientists have contributed to the study of labor market issues. For example, S. Yu. Tsekhla, N. A. Simchenko and E. A. Polishchuk were engaged in the study of regularities and mechanisms of employment in certain subjects of the Russian Federation. The authors have identified the main causes of lack of proportions in the labor market, and made certain recommendations to reduce this imbalance, taking into account the current economic conditions [16].

An indicator of the stage of the country economic development can be the professional structure of the population [17].

The production system of industrialized countries is described by the post-industrial development phase, characterized by the following indicators of labor potential: highly skilled labor with a wide specialization (nature of labor, depth of division of labor according to specialization and qualification); prevalence of professional managers, and technical experts (proportions in the professional structure) [18].

\section{Results}

The study shows the employment of older people should take into account their higher potential compared to the overall employment. Employment of older people is inherently limited, since their ability to choose work activities is significantly narrowed by a biased attitude towards an elderly person [19].

Empowerment of older people can be achieved by improving organizational systems, such as training, developing information systems, as well as by increasing their motivation and readiness to learn [20].

Methodical approaches to the study of employment of older people are aimed at studying the qualitative characteristics: labor productivity, quality of working life, wages [21].

The analysis showed that older people provide productive work with high labor productivity - this deserves a large labor income, but at the same time, there must be observed a balance of interests of workers of other ages [22].

The purpose of research was to develop an information model that takes into account the qualitative characteristics of the requirements of seniors and employers.

Comprehensive analysis allowed to develop an informational model for researching the preparation of employment of elderly people in rural areas (Figure 1).

The study was conducted in rural areas of the Chelyabinsk region, included various age and occupational groups. The result of the using scientific methods was construction the information model of providing employment for older people in rural areas. It is an applied study in terms of components. 
Employment of elderly people in the village of Chelyabinsk region is characterized by an imbalance in age, a high unevenness of the level of employment among age groups. The current situation points to the need to develop differentiated systems of influence on increasing the employment of the elderly.

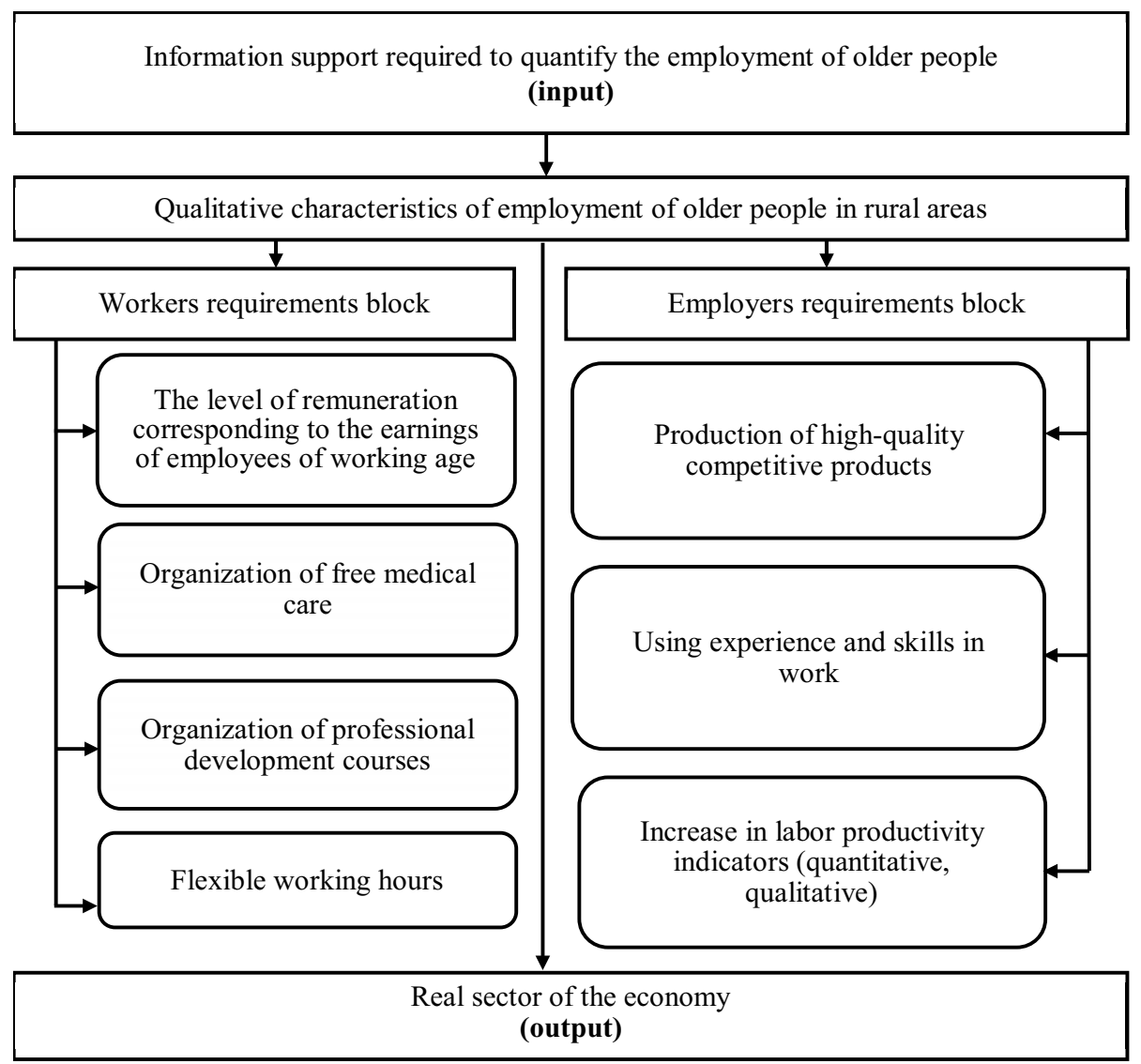

Fig. 1. Information model for providing employment of senior population in rural areas (developed by the authors).

To assess the quantitative level of employed elderly people in rural areas the following indicators were used:

- $\quad$ proportion of the employed elderly population in rural areas to the total employed population;

- employment rate of older people in rural areas;

- $\quad$ proportion of the population over working age in the total resident population of rural areas.

The proportion of employed elderly people was calculated by the formula:

$$
\mathrm{PEm}_{\text {sen }}=\frac{\mathrm{Em}_{\text {sen }}}{E \mathrm{~m}_{\mathrm{gen}}} * 100
$$

$\mathrm{PEm}_{\text {sen }}$ - proportion of employed elderly people in the total employed population of rural areas, \%;

$\mathrm{Em}_{\text {sen }}$ - total number of employed seniors in rural area, men;

$\mathrm{Em}_{\mathrm{gen}}-$ total employed population in rural area, men. 
The labor resources of the population of retirement age (who have retained the ability and desire to work) are not fully used, despite their vast experience, knowledge, skills accumulated over the years of professional activity, and high qualifications. This testifies to an irrational approach to the use of labor resources, the omission of significant labor potential, which prevents the increase in the efficiency of the real sector of the economy and reduces the level of sustainability of the socio-economic development of rural areas. The results of calculating the proportion of employed people over the working age in the total number of employed rural population substantiate the judgment about the instability and the tendency to decrease this indicator (Table 1).

Table 1. Initial data and calculation of the proportion of employed older people.

\begin{tabular}{|c|c|c|c|c|c|c|c|}
\hline Indicator & $\mathbf{2 0 1 2}$ & $\mathbf{2 0 1 3}$ & $\mathbf{2 0 1 4}$ & $\mathbf{2 0 1 5}$ & $\mathbf{2 0 1 6}$ & $\mathbf{2 0 1 7}$ & $\mathbf{2 0 1 8}$ \\
\hline Em $_{\text {gen }}$ & 85600.0 & 84402.0 & 82481.0 & 82061.0 & 79856.0 & 78084.0 & 77079.0 \\
\hline Em $_{\text {sen }}$ & 20030.0 & 19497.0 & 17651.0 & 16823.0 & 14534.0 & 13274.0 & 12641.0 \\
\hline PEm $_{\text {sen }}$ & 23.4 & 23.1 & 21.4 & 20.5 & 18.2 & 17.0 & 16.4 \\
\hline
\end{tabular}

Note: compiled and calculated by the authors according to the data of the Federal State Statistics Service for the Chelyabinsk Region.

The employment rate of older people in rural areas is calculated as the ratio of the employed population over the working age to the total population over the working age. Table 2 shows the initial data and calculation results for rural areas of the Chelyabinsk region. There is the formula for calculating the employment rate of older people in rural areas:

$$
\mathrm{P}_{\mathrm{emsen}}=\frac{\mathrm{Em}_{\mathrm{sen}}}{\mathrm{Popl}_{\mathrm{sen}}}
$$

$\mathrm{P}_{\mathrm{emsen}}$ - employment rate of older people in the total number of seniors in rural areas;

$\mathrm{Em}_{\text {sen }}$ - employed seniors in rural areas, thousand people;

Popl $1_{\text {sen }}$ - total number of seniors in rural areas, thousand people.

Table 2. Initial data and calculation of the employment rate of older people.

\begin{tabular}{|c|c|c|c|c|c|c|c|}
\hline Indicator & $\mathbf{2 0 1 2}$ & $\mathbf{2 0 1 3}$ & $\mathbf{2 0 1 4}$ & $\mathbf{2 0 1 5}$ & $\mathbf{2 0 1 6}$ & $\mathbf{2 0 1 7}$ & $\mathbf{2 0 1 8}$ \\
\hline Emsen & 20.030 & 19.412 & 17.321 & 16.412 & 14.374 & 13.274 & 12.641 \\
\hline Popl $_{\text {sen }}$ & 132.055 & 135.423 & 138.916 & 142.448 & 146.618 & 150.134 & 132.364 \\
\hline$P_{\text {emsen }}$ & 0.152 & 0.143 & 0.125 & 0.115 & 0.098 & 0.088 & 0.096 \\
\hline
\end{tabular}

Note: compiled and calculated by the authors according to the data of the Federal State Statistics Service for the Chelyabinsk Region.

Ensuring employment of the population older than the working age is not a priority in the socio-economic policy of the rural areas of the Chelyabinsk region, which is confirmed by the revealed tendency towards a decrease in the value of the employment rate of elderly people in the countryside over seven years the indicator decreased from 0.152 to 0.096 .

The proportion of the population over the working age in the total resident population is calculated as the ratio of the population over the working age to the total population of rural areas. The initial data and calculation results are presented in table (Table 3).

Table 3. Initial data and calculation of the proportion of the population over working age in rural areas.

\begin{tabular}{|c|c|c|c|c|c|c|c|}
\hline Indicator & $\mathbf{2 0 1 2}$ & $\mathbf{2 0 1 3}$ & $\mathbf{2 0 1 4}$ & $\mathbf{2 0 1 5}$ & $\mathbf{2 0 1 6}$ & $\mathbf{2 0 1 7}$ & $\mathbf{2 0 1 8}$ \\
\hline Popl $_{\text {sen }}$ & 132055.0 & 135423.0 & 138916.0 & 142448.0 & 146618.0 & 150134.0 & 132364.0 \\
\hline Popl $1_{\text {rgen }}$ & 533070.0 & 530440.0 & 526518.0 & 522968.0 & 523066.0 & 523589.0 & 520956.0 \\
\hline$P_{\text {sen }}$ & 24.8 & 25.5 & 26.4 & 27.2 & 28.0 & 28.7 & 25.4 \\
\hline
\end{tabular}

Note: compiled and calculated by the authors according to the data of the Federal State Statistics Service for the Chelyabinsk Region. 
For the calculation the following formula was used:

$$
\mathrm{P}_{\text {sen }}=\frac{\text { Popl }_{\text {sen }}}{\text { Popl }_{\text {rgen }}} * 100
$$

$\mathrm{P}_{\text {sen }}$ - proportion of older than working age people in the total rural population, \%;

Popl $_{\text {sen }}$ - total number of seniors in rural areas, men;

Popl $1_{\text {rgen }}$ - total rural population, men.

The share of the elderly population in rural areas in 2018 amounted to $25.4 \%$ of the total rural population. Moreover, an increasing dynamics of this indicator has been observed since 2012 (Table 3). Consequently the low level of employment of people of retirement age with an increasing share of this age group in the total population of rural areas has a negative impact on the level of sustainability of socio-economic development of the village.

\section{Discussion}

Hypothesis 1 . Seniors have vast experience, knowledge, are highly qualified and capable of non-standard solution of professional tasks.

This potential is not fully used, which does not allow improving the efficiency of the real sector of the economy. The results show that the proportion of seniors employed in the countryside is unstable. Over the past seven years it has dropped from 23.4 to $16.4 \%$.

Hypothesis 2. Employment of elderly people in rural areas is not a priority.

The proportion of employed elderly people in the total number of seniors in rural areas of the Chelyabinsk region tends to steadily decrease. For the last seven years the figure fell from 0.152 to 0.096 . The result confirms the hypothesis put forward.

Hypothesis 3. The increase in the proportion of seniors in rural areas should have a significant impact on the socio-economic development of the territories.

The proportion of older than working age people in the total rural population has increased over the past seven years from 24.8 to $25.4 \%$. This indicates the increasing role of the elderly population in the rural economy.

The study also carried out a quantitative assessment of the employment of the population in rural areas of the Chelyabinsk region, taking into account the grouping by gender and age (Table 4).

Table 4. The share of the employed population in rural areas of the Chelyabinsk region (taking into account the division by gender and age).

\begin{tabular}{|c|c|c|}
\hline \multirow{2}{*}{$\begin{array}{c}\text { Age group, } \\
\text { years }\end{array}$} & \multicolumn{2}{|c|}{ Rural population } \\
\cline { 2 - 3 } & Men & Women \\
\hline $60-64$ & $44.90 \%$ & $55.10 \%$ \\
\hline $65-69$ & $41.89 \%$ & $58.11 \%$ \\
\hline $70-74$ & $37.53 \%$ & $62.47 \%$ \\
\hline $75-79$ & $30.39 \%$ & $69.61 \%$ \\
\hline $80-84$ & $27.06 \%$ & $72.94 \%$ \\
\hline $85-89$ & $22.88 \%$ & $77.12 \%$ \\
\hline $90-94$ & $15.28 \%$ & $84.72 \%$ \\
\hline
\end{tabular}

Note: compiled and calculated by the authors according to the data of the Federal State Statistics Service for the Chelyabinsk Region.

In the study a tendency was established for a decrease in the proportion of working men in the total number of employed people with an increase in the age range. Taking into account the division of the population into seven age groups, the share of employed men is reduced by almost three times, while the employment of women is increasing by $30 \%$. 


\section{Conclusion}

In the course of the study the practical significance of the developed information model for ensuring the employment of older people in rural areas was proved. Labor using of senior people who have retained ability and desire to work is particularly important for solving the problem of rational using labor resources. Within the framework of the proposed information model for ensuring employment of the population over the working age the requirements of workers in this category and their employers are taken into account, also it is assumed that modern technologies are used in management, which makes it possible to effectively develop the industrial and social infrastructure of rural areas, contributing to the sustainable development of this territories. All this should be taken into account in the strategic programs of the region and some rural areas development.

\section{Acknowledgement}

This work was supported by the South Ural State Agrarian University and the Chelyabinsk State University.

\section{References}

1. V.N. Bobkov, V.G. Kvachev, N.V. Loktyukhina, M. Ricceri, Economy of Region 13(3), 672-683 (2017) DOI: 10.17059/2017-3-3

2. V.N. Bobkov, V.G. Kvachev, I.V. Novikova, Economy of Region 14(2), 366-379 (2018) DOI: 10.17059/2018-2-3

3. M.Yu. Dolomatov, V.V. Martynov, N.A. Zhuravleva, E.Sh. Zakieva, Economy of Region 13(1), 70-79 (2017) DOI: 10.17059/2017-1-7

4. G.Yu. Gagarina, R.V. Gubarev, E.I. Dzyuba, F.S. Fayzullin, Economy of Region 13(4), 1080-1094 (2017) DOI: 10.17059/2017-4-9

5. V.V. Andreev, Economy of Region 13(3), 803-811 (2017) DOI: 10.17059/2017-3-13

6. E.L. Andreeva, A.F. Linetsky, A.V. Ratner, D.E. Kuznetsova, Economy of Region 12(4), 1050-1059 (2016) DOI: 10.17059/2016-4-7

7. L.V. Shkvarya, E.D. Frolova, Economy of Region 13(2), 570-578 (2017) DOI: $10.17059 / 2017-2-21$

8. V.V. Kislitsyna, L.S. Cheglakova, V.M. Karaulov, A.N. Chikisheva, Economy of Region 13(2), 369-380 (2017) DOI: 10.17059/2017-2-4

9. O.A. Kozlova, R.V. Nifantova, M.N. Makarova, Economy of Region 13(2), 511-523 (2017) DOI: 10.17059/2017-2-16

10. V.N. Leksin, B.N. Porfiryev, Economy of Region 13(4), 985-1004 (2017) DOI: 10.17059/2017-4-2

11. A.V. Vasilyeva, Economy of Region 13(3), 812- 826 (2017) DOI: 10.17059/2017-314

12. L. Lebedeva, G. Feiguine, Mediterranean Journal of Social Sciences 6(4), 388-394 (2015) DOI: 10.5901/mjss.2015.v6n4s4p388

13. V.A. Iontsev, A.G. Magomedova, Economy of Region 3, 89-102 (2015) DOI: 10.17059/2015-3-8

14. R.M. Nizhegorodtsev, E.I. Piskun, V.V. Kudrevich, Economy of Region 13(1), 38-48 (2017) DOI: $10.17059 / 2017-1-4$ 
15. V.V. Lokosov, Ye.V. Ryumina, V.V. Ulyanov, Economy of Region 4, 185-196 (2015) DOI: 10.17059/2015-4-15

16. S.Yu. Tsekhla, N.A. Simchenko, E.A. Polishchuk, Economy of Region 3, 149-160 (2015) DOI: 10.17059/2015-3-13

17. O.V. Gokova, A.M. Kiseleva, Economy of Region 13(2), 537-549 (2017) DOI: 10.17059/2017-2-18

18. O. Rubaeva, E. Pogartseva, E. Kot, T. Nikitina, Journal of Environmental Management and Tourism 9(7), 1512-1524 (2018) DOI: https://doi.org/10.14505//jemt.9.7(31).15

19. M.M. Ali, V. Rattanawiboonsom, C.M. Perez, A.A. Khan, Economy of Region 13(2), 381-395 (2017) DOI: 10.17059/2017-2-5

20. A.Yu. Davankov, D.Yu. Dvinin, Ye.A. Postnikov, Economy of Region 12(4), 10281039 (2016) DOI: 10.17059/2016-4-5

21. S.A. Dyatlov, G.F. Feygin, L.F. Lebedeva, Economy of Region 13(4), 1151-1163 (2017) DOI: 10.17059/2017-4-14

22. M.Yu. Malkina, Economy of Region 13(1), 49-62 (2017) DOI: 10.17059/2017-1-5 